\title{
A BUROCRATIZAÇÃO DA SEGURANÇA INTERNACIONAL: A PROLONGADA ASSISTÊNCIA HUMANITÁRIA DA UNRWA AOS REFUGIADOS DA PALESTINA NO ORIENTE MÉDIO $^{1}$
}

\author{
THE BUREAUCRATIZATION OF INTERNATIONAL SECURITY: UNRWA'S PROTRACTED \\ HUMANITARIAN ASSISTANCE TO PALESTINE REFUGEES IN THE MIDDLE EAST
}

Claudia Stephan

Doutoranda em Ciência Política na Universidade Federal do Paraná, Curitiba, Paraná, Brasil, claudia.stephan@hotmail.com

\section{Resumo}

O Plano de Partilha da Palestina proposto pela Organização das Nações Unidas (ONU) em 1947 gerou o conflito Árabe-Israelense de 1948, o qual resultou em milhares de refugiados da Palestina e demandou uma ação humanitária por parte da ONU para conter a instabilidade nessa região do Oriente Médio. A situação de refúgio dos palestinos perdura há 70 anos e não há previsão de solução permanente. A assistência humanitária prestada pela Agência das Nações Unidas de Assistência aos Refugiados da Palestina (UNRWA), estabelecida em caráter temporário, tem sido renovada há 68 anos. Neste artigo, o objetivo é analisar historicamente (e criticamente)o papel da UNRWA e suas implicações para as negociações do conflito Israel-Palestina. Argumenta-se que a agência cumpre um imprescindível papel humanitário, amenizando a situação dos refugiados até que uma solução permanente seja negociada entre as partes. Entretanto, a agência desempenha funções similares a um Estado na medida em que presta serviços essenciais aos refugiados, como nas áreas de educação e saúde, mas expressa, ao mesmo tempo, a burocratização da questão palestina na ONU, tornando-se, por isso, um empecilho às negociações de paz na medida em que perdeu seu caráter temporário ao assumir funções e tarefas próprias de um Estado.

Palavras-chave: UNRWA; Refugiados Palestinos; Assistência Humanitária; Conflito Israel-Palestina; Segurança Internacional.

\footnotetext{
${ }^{1}$ O presente artigo foi realizado com apoio da Coordenação de Aperfeiçoamento de Pessoal de Nível Superior Brasil (CAPES) - Código de Financiamento o01. Este artigo discute os resultados da dissertação da autora (2015) e, portanto, pode apresentar dados não atualizados. Entretanto, não ficam prejudicadas a análise ou o panorama do funcionamento da UNRWA.
} 


\section{ABSTRACT}

The Palestine Partition Plan proposed by the United Nations (UN) in 1947 led to the Arab-Israeli conflict of 1948, which resulted in thousands of Palestinian refugees and demanded a humanitarian action on the part of that international organization to contain the instability in this region of the Middle East. The Palestinian refugee situation endures for 70 years and there are no signs of a permanent solution. The humanitarian assistance provided by the United Nations Relief and Works Agency for Palestine Refugees in the Near East (UNRWA), established on a temporary basis, has been renewed for 68 years. The aim of this paper is to analyze historically and critically the role of UNRWA and its implications for the Israeli-Palestinian peace talks. We argue that the agency plays an humanitarian role, alleviating the refugees situation until the parties negotiate a permanent solution. However, the agency performs functions similar to a State insofar as it provides services to refugees as in the areas of education and health, but at the same time expresses the bureaucratization of the Palestine question at the UN, thereby becoming an obstacle to the peace talks insofar as it has lost its temporary character by taking on functions and tasks proper of a State.

Key words: UNRWA; Palestine Refugees; Humanitarian Assistance; Israel-Palestine Conflict; International Security.

\section{INTRODUÇÃO}

Antes da criação da ONU em 1945, a região da Palestina foi objeto de interesse da primeira organização internacional de segurança coletiva, a Liga das Nações, por meio do estabelecimento de um Sistema de Mandatos ${ }^{2}$ na região do Oriente Médio (1922). O interesse dos palestinos pela independência diante do controle britânico e a criação do Estado da Palestina transformaram-se em uma disputa territorial, devido à crescente imigração de judeus oriundos da Europa movidos pelo ideal sionista de estabelecer um 'lar nacional judaico' nessa região. O aumento dos enfrentamentos entre os movimentos palestinos e judaicos e o fracasso das tentativas britânicas de negociar uma solução que satisfizesse as duas partes fizeram com que o governo britânico levasse a questão para ser decidida na ONU.

O Plano de Partilha da Palestina proposto pela Resolução 181(II) da Assembleia Geral das Nações Unidas (AGNU/UNGA), em 29 de novembro de 1947, gerou o conflito Árabe-Israelense de 1948 que resultou em milhares de refugiados da Palestina e demandou uma ação por parte da comunidade internacional para conter a instabilidade na região. O fracasso das negociações para um acordo de paz e a retomada do Plano de Partilha, que previa tanto a criação do Estado da Palestina quanto do Estado de Israel, demandaram a criação de uma agência humanitária para assistir, temporariamente, aos refugiados do conflito. Em 1949, a AGNU aprovou a criação da Agência das Nações Unidas de Assistência aos Refugiados da Palestina (UNRWA) 3 para prestar ajuda humanitária até que uma solução permanente fosse negociada. Entretanto, o conflito continua sem solução após 68 anos de mandatos.

Este artigo analisa historicamente e criticamente o papel da UNRWA e suas implicações para as negociações do conflito Israel-Palestina. Argumenta-se que essa agência cumpre um imprescindível

\footnotetext{
${ }^{2}$ O Sistema de Mandatos foi instituído pela Liga das Nações, em caráter transitório, para promover a independência gradual dos territórios de domínio alemão e turco-otomano ao final da I Guerra Mundial.

${ }^{3}$ A tradução literal é 'Agência de Socorro e Obras Públicas das Nações Unidas para os Refugiados da Palestina no Oriente Próximo'. Optou-se aqui pela versão mais curta utilizada no portal da agência no Brasil.
} 
papel humanitário, amenizando a situação dos refugiados à espera de uma solução permanente entre as partes. Entretanto, a agência desempenha funções similares a de um Estado na medida em que presta serviços essenciais aos refugiados em áreas como saúde e educação, mas é parte, ao mesmo tempo, da burocratização da questão palestina na ONU. Burocratização, aqui, é sinônimo da crescente normatividade (por meio de resoluções, acordos e normas internacionais, dentre outras) e da criação de várias estruturas (comitês, comissões, programas, escritórios) destinadas ao tratamento da questão Palestina dentro da ONU. Esse processo tornou-se, por isso, um obstáculo às negociações de paz, pois favorece o adiamento de uma das questões centrais envolvidas nessas negociações: a solução para o problema dos refugiados. A despeito de toda a atenção dada à questão Palestina pela ONU, a situação de refúgio dos palestinos perdura há 70 anos e não há previsão de solução permanente. É considerada como "a maior e mais antiga situação prolongada de refúgio no mundo", representando 40\% do total mundial de pessoas que se enquadram nesse status (UNHCR, 2006, p. 112; UNRWA, 2016).

O artigo está organizado em três seções. A primeira explica o que significa falar em burocratização da questão Palestina na ONU/UNRWA. A segunda seção, por sua vez, apresenta o caso da prolongada assistência humanitária da UNRWA. Por fim, a terceira seção discute as consequências da burocratização e do impasse dos refugiados palestinos para as negociações do conflito Israel-Palestina.

\section{A BUROCRATIZAÇÃO DA QUESTÃO PALESTINA NA ONU/UNRWA}

A compreensão do processo de burocratização da questão Palestina na ONU, e consequentemente na UNRWA, passa pelo histórico do próprio conflito Árabe-Israelense e pela política de segurança internacional. As ameaças à paz e à segurança internacional são prerrogativas da organização internacional, mais especificamente do Conselho de Segurança das Nações Unidas (CSNU/UNSC). Quando um conflito em âmbito nacional é percebido como uma ameaça à segurança internacional, frequentemente após diversas tentativas de solucioná-lo, passa a ser tema da agenda do CSNU, que irá propor soluções temporárias ou permanentes a fim de retomar a estabilidade da ordem nacional ou internacional.

\footnotetext{
O Conselho de Segurança assume a liderança na determinação da existência de uma ameaça à paz ou ato de agressão. O Conselho apela às partes em disputa para que resolvam a controvérsia por meios pacíficos e recomenda métodos de ajuste ou os termos do acordo. Em alguns casos, o Conselho de Segurança pode recorrer à aplicação de sanções ou mesmo autorizar o uso da força para manter ou restaurar a paz e a segurança internacional (UNSC, 2016).
}

O conflito Árabe-Israelense de 1948 foi um dos casos levados ao CSNU, oficializado como ameaça à paz por meio da Resolução $54(\mathrm{~S} / 902)$ de 15 de julho daquele ano, que ordenava também um cessar-fogo aos beligerantes (UN, 2008, p. 10). Os principais pontos de disputa entre Israel e Palestina são o território (fronteiras), os refugiados palestinos (direito de retorno) e a ocupação militar (bloqueio, anexação e violações de direitos humanos). Essa resolução teve como base a Carta das Nações Unidas de 1945, Capítulo VII - Ação Relativa a Ameaças à Paz, Ruptura da Paz e Atos de Agressão, Artigo 39: 
O Conselho de Segurança determinará a existência de qualquer ameaça à paz, ruptura da paz ou ato de agressão, e fará recomendações ou decidirá que medidas deverão ser tomadas de acordo com os Artigos 41 e 42, a fim de manter ou restabelecer a paz e a segurança internacionais (UNICRIO, 2015).

O fracasso das mediações da ONU demandou uma ação humanitária para assistir aos milhares de refugiados da Palestina, a fim de estabilizar a ordem interna do recém fundado Estado de Israel e da região. Nesse contexto, a Assembleia Geral das Nações Unidas (AGNU) aprovou a criação da UNRWA em 08 de dezembro de 1949, por meio da Resolução 302 (IV).

A questão Palestina é, portanto, o resultado do estabelecimento de apenas um dos Estados previstos no Plano de Partilha da ONU - o Estado judaico. Pode ser definida como a busca pela realização dos direitos inalienáveis do povo palestino constantes na Carta das Nações Unidas (1945) e na Declaração Universal dos Direitos Humanos (DUDH, 1948), oficializados pelas Resoluções 2535B (XXIV) de 1969 e 3236 (XXIX) de 1974. Os direitos de autodeterminação, independência e soberania nacional, e de retorno às suas residências de origem ainda não foram estendidos aos palestinos, embora, desde 1974, a questão Palestina integre a agenda anual da AGNU (UN, 2008, p. 23-24).

Nesse sentido, acumulou-se uma normatividade (resoluções, acordos, relatórios, normas internacionais etc.) que, por sua vez, demandou a criação de várias estruturas especializadas (comitês, comissões, programas, escritório, divisão, agência subsidiária etc.) para tratar a questão Palestina no

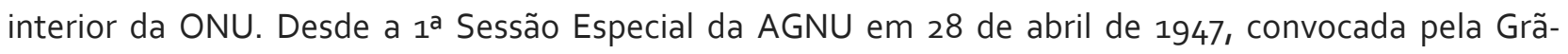
Bretanha para resolver a disputa entre palestinos e judeus, até a concessão do status de Estado não membro observador para a Palestina em 2012, foram criadas 14 estruturas relacionadas apenas à questão (Quadro 1). As estruturas ${ }^{4}$ podem ser categorizadas pela sua função, quais sejam: investigação (1 comitê especial), negociação (2 comissões, 1 comitê e 1 escritório), supervisão (1 organização), assistência humanitária (1 órgão, 1 agência e 1 programa), conscientização (1 sistema de informação), direitos (1 comitê e 1 unidade especial, hoje divisão), registro (1 órgão) e observação (1 missão permanente).

Da mesma maneira, foram aprovadas 28 resoluções 5 fundamentais sobre a questão Palestina, sendo 17 da AGNU e 11 do CSNU, no intervalo entre 1947 e 2012. Enquanto o número de estruturas permanece igual, a normatividade cresce na medida em que o conflito continua sem solução. Além disso, diversos programas e agências das Nações Unidas também trabalham em alguma medida com a questão Palestina, como UNDP/PAPP, UNICEF, UNIFEM, WFP, FAO, WHO, UNFPA, OHCHR, UNIDO, ILO, OCHA, World Bank e comitês organizados junto à sociedade civil em diversos países (UN, 2008, p. 8288).

\footnotetext{
4 Estruturas físicas e "atividades [com] uma certa regularidade" (ALMOND e POWELL, 1980, p. 19).

${ }^{5} \mathrm{O}$ artigo enumera as principais resoluções (e estruturas) relacionadas à questão Palestina. Porém, há muitas outras que reiteram o conteúdo das resoluções fundamentais para a compreensão do conflito Israel-Palestina. Di Mauro (2004) cita 627 resoluções, apenas da AGNU, relacionadas ao conflito entre 1947 e 2002.
} 


\section{QUADRO 1 - ESTRUTURA ${ }^{6}$ E NORMATIVIDADE7 RELACIONADAS À QUESTÃO PALESTINA NA}

ONU

\begin{tabular}{|c|c|}
\hline \multicolumn{2}{|c|}{ QUESTÃO PALESTINA NA ONU } \\
\hline ESTRUTURA & NORMATIVIDADE \\
\hline 1947 UN Special Committee on Palestine (UNSCOP) [N] & 1947 Resolução 181 (II) da AGNU \\
\hline $\begin{array}{l}1948 \text { UN Truce Commission For Palestine (UNTCP) [N] } \\
\text { UN Truce Supervision Organization (UNTSO) [S] }\end{array}$ & $\begin{array}{l}1948 \text { Resolução } 242 \text { (III) e } 194 \text { (III) da AGNU e } 50 \text { e 54(S-/902) } \\
\text { do CSNU } \\
\text { Proclamação do Estado de Israel }\end{array}$ \\
\hline UN Relief for Palestine Refugees (UNRPR) [A] & 1949 Resolução 302 (IV) e 273 (III) da AGNU \\
\hline UN Conciliation United Nations Commission for Palestine & Admissão de Israel como Estado Membro da ONU. \\
\hline & 1950 Resolução 394 (V) da AGNU \\
\hline & 1967 Resolução 242 do CSNU \\
\hline $\begin{array}{l}1949 \text { UN Relief and Works Agency for Palestine Refugees in } \\
\text { the Near East (UNRWA) [A] }\end{array}$ & 1969 Resolução 2535B da AGNU \\
\hline & 1973 Resolução 338 do CSNU \\
\hline $\begin{array}{l}1968 \text { Special Committee to Investigate Israeli Practices } \\
\text { Affecting the Human Rights of the Palestinian People and } \\
\text { other Arabs of the Occupied Territories [I] }\end{array}$ & $\begin{array}{l}1974 \text { Resoluções } 3236 \text { e } 3237 \text { XXIX da AGNU } \\
\text { OLP admitida como Observadora da ONU } \\
\text { Questão Palestina como Autodeterminação dos Povos }\end{array}$ \\
\hline & 1975 Resolução 3376 (XXX) da AGNU \\
\hline 1975 Committee on the Exercise of the Inalienable Rights of & 1977 Resolução 32/40B da AGNU \\
\hline the Palestine People (CEIRPP) [D] & 1978 Resolução 33/147 da AGNU \\
\hline (later Palestinian Rights Committee) & 1979 Resolução 446 do CSNU \\
\hline & 1980 Resolução 478 do CSNU \\
\hline $\begin{array}{l}1977 \text { Special Unit on Palestinian Rights at the UN Secretariat } \\
\text { (later Division for Palestinians Rights) [D] } \\
\text { United Nations Information System on the Question of } \\
\text { Palestine (UNISPAL) [C] }\end{array}$ & $\begin{array}{l}1983 \text { International Conference for the Question of Palestine } \\
\text { Geneva Declaration of Palestine } \\
\text { Programme of Action for the Achievement of Palestinians Rights }\end{array}$ \\
\hline & $\begin{array}{l}1988 \text { Resolução } 43 / 177 \text { da AGNU e } 608 \text { do CSNU } \\
\text { Reconhecimento da Proclamação do Estado da Palestina }\end{array}$ \\
\hline $\begin{array}{l}1978 \text { Programme of Assistance to the Palestinian People } \\
\text { (PAPP/UNDP) [A] }\end{array}$ & 1990 Resolução 672 do CSNU \\
\hline & 1991 Madrid Peace Conference \\
\hline $\begin{array}{l}1994 \text { Office of the United Nations Special Coordinator for the } \\
\text { Middle East Peace Process [N] }\end{array}$ & $\begin{array}{l}1993 \text { ONU participa das negociações multilaterais } \\
\text { The Oslo Accords } \\
\text { Declarations of Principles on Interim Self-Government }\end{array}$ \\
\hline $\begin{array}{l}2004 \text { Register of Damage (caused by the construction of the } \\
\text { wall in the occupied Palestinian territory) [R] }\end{array}$ & $\begin{array}{l}1994 \text { Resolução } 904 \text { do CSNU } \\
\text { Palestinian National Authority (PNA) }\end{array}$ \\
\hline Permanent Observer Mission of the State of Palestine to the & $\begin{array}{l}1995 \text { Israeli-Palestinian Interim Agreement on the West Bank and } \\
\text { the Gaza Strip }\end{array}$ \\
\hline United Nations [O] & 1996 Palestinian Legislative Council (PLC) \\
\hline & 2000 Camp David Accords \\
\hline & 2002 Resolução 1435 do CSNU \\
\hline & $\begin{array}{l}2003 \text { Peace Initiatives: Middle East Quartet / The Road Map / The } \\
\text { Geneva Initiative }\end{array}$ \\
\hline & $\begin{array}{l}2004 \text { ICJ Advisory Opinion on the Legal Consequences of the } \\
\text { Construction of the Wall in the Occupied Palestinian Territory }\end{array}$ \\
\hline & 2005 Resolução 59/179 da AGNU \\
\hline & 2007 Annapolis Conference \\
\hline & 2009 Resolução 1860 do CSNU \\
\hline & $\begin{array}{l}2012 \text { Resolução 66/17, 66/19 e } 67 / 19 \text { da AGNU } \\
\text { Report of the United Nation Fact Finding Mission on the Gaza } \\
\text { Conflict (Goldstone Report) } \\
\text { Palestine Admitted as Non Member Observer State }\end{array}$ \\
\hline
\end{tabular}

Fonte: Elaboração própria (2016).

A Agência das Nações Unidas de Assistência aos Refugiados da Palestina (UNRWA) é a mais importante dessas estruturas, pois é responsável pela manutenção do compromisso assumido pela comunidade internacional de assegurar os direitos dos palestinos e de promover estabilidade até que uma solução permanente seja negociada. Aprovada como um paliativo para a situação socioeconômica

${ }^{6}$ Categorias das estruturas apresentadas: negociação [N], supervisão [S], assistência humanitária [A], investigação $[1]$, direitos [D], conscientização [C], registro [R] e observação [O].

${ }^{7}$ AGNU - Assembleia Geral das Nações Unidas; CSNU - Conselho de Segurança das Nações Unidas. 
dos refugiados em 1949, ao longo das décadas adquiriu funções similares de um Estado ao preencher a lacuna da Palestina de facto e realizar obrigações que caberiam ao Estado de Israel ${ }^{8}$.

A assistência humanitária oferecida pela UNRWA não é restrita aos refugiados da Palestina que se encontram nos designados territórios palestinos da Cisjordânia e da Faixa de Gaza, mas também aqueles que buscaram refúgio nos países vizinhos, Jordânia, Líbano e Síria. Cada uma dessas áreas assistidas pela agência possui um escritório, além dos escritórios do Comissário Geral e da ViceComissária Geral ${ }^{9}$ e de outros dois escritórios de representação nos Estados Unidos (Nova lorque e Washington), um na Bélgica (Bruxelas) e um no Egito (Cairo) (UNRWA(a), 2016).

Essa complexa estrutura ainda conta com escritórios do(a) Porta-Voz e do Tribunal de Disputas Internas da UNRWA, Comitê de Justiça Interna, Unidade de Suporte aos Programas e Planejamento de Recursos e Projetos. Ademais, outros 11 departamentos são responsáveis pelas áreas de Fiscalização Interna, Relações Externas e Comunicação, Assuntos Legais, Microfinanciamento, Educação, Saúde, Assistência Social, Infraestrutura e Aperfeiçoamento dos Campos, Recursos Humanos, Finanças e Suporte Administrativo. A parte administrativa da agência concentra-se nas sedes da Jordânia (Amã) e Jerusalém, enquanto a assistência propriamente dita distribui-se nas cinco áreas de operação. (UNRWA(a), 2016). A UNRWA reporta-se apenas à Assembleia Geral, entretanto suas decisões dependem da aprovação do Secretário geral da $\mathrm{ONU}^{10}$ e está sujeita a auditorias a cada dois anos para prestar contas à AGNU (UNRWA FAO, 2016).

\footnotetext{
${ }^{8}$ As obrigações legais internacionais que cabem ao Estado de Israel em relação ao conflito per se e à ocupação militar dos territórios palestinos e bloqueio à Faixa de Gaza constam na Carta da ONU (como Estado membro 'legalmente' vinculado), nas resoluções da AGNU e do CSNU, e nas normas internacionais, especialmente do Direito Internacional Humanitário, do Direito Internacional dos Refugiados e do Direito Internacional dos Direitos Humanos. Devido à complexidade e à extensão desse debate, o tema não será abordado neste artigo.
}

9 Pierre Krähenbühl (2014 - presente) e Sandra Mitchell (2015 - presente).

${ }^{10}$ António Guterres (2017 - presente). 


\section{FIGURA 1 - ESTRUTURA ORGANIZACIONAL DA UNRWA}

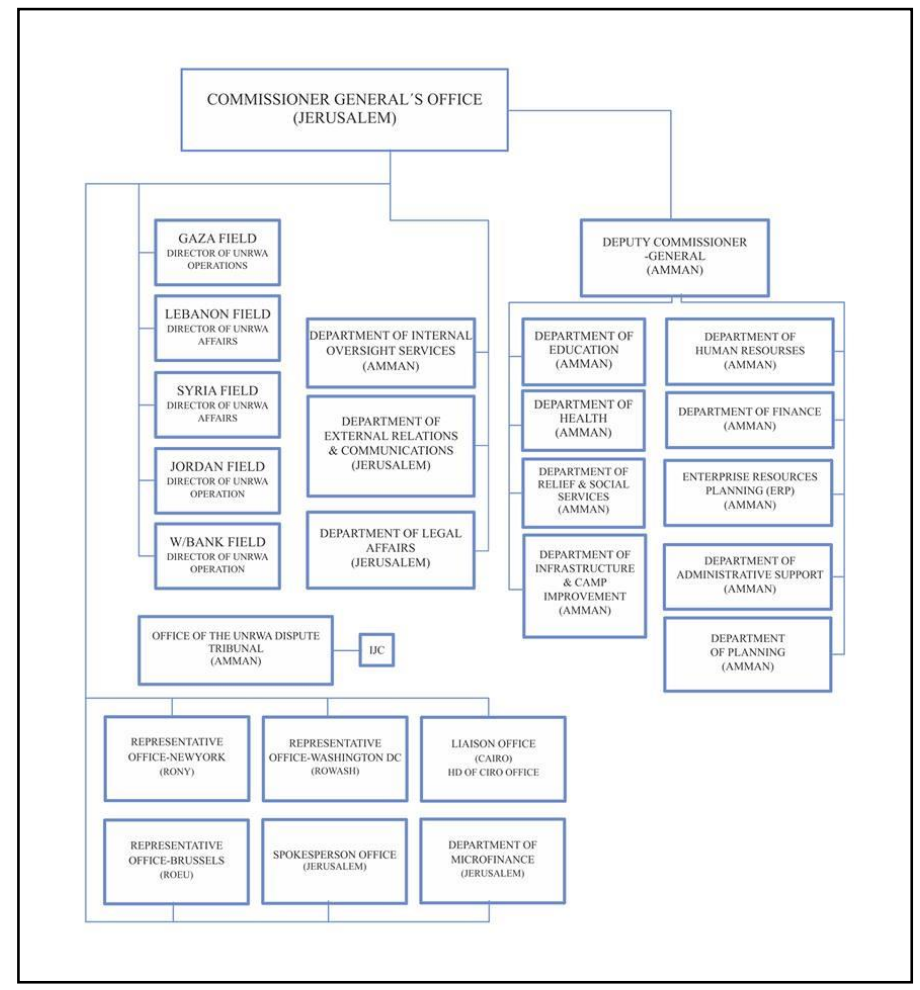

Fonte: UNRWA (2016).

Esse conjunto estrutura-normatividade representa a burocratização da questão Palestina na ONU/UNRWA. Uma complexa rede institucional especializada nessa questão, articulada para ser temporária, mas que, por diversas razões, persiste por sete décadas. Nesse sentido, alguns pontos devem ser enfatizados. Em primeiro lugar, a burocratização é o resultado do fracasso das mediações e negociações de paz do conflito Árabe-Israelense. Entretanto, não significa que a ONU não tenha cumprido o seu papel de mediadora da paz e da segurança internacional, mas que há muitas limitações em relação ao seu desempenho de modo geral. Isso se deve às próprias limitações do sistema de segurança coletiva, que é constituído de Estados soberanos e não tem autoridade supranacional para interferir nas questões domésticas, salvo as intervenções aprovadas pelo CSNU. Além disso, a política internacional é, também, a busca pelos objetivos e interesses desses Estados - não apenas para a cooperação, muitas vezes entrando em conflito com o Direito Internacional. Daí a existência de disputas e o imperativo de ignorar certas normas internacionais.

\footnotetext{
A postura realista, no âmbito das relações internacionais, encaixa-se muito bem na conhecida teoria dualista fundamentadora do Direito Internacional Público. Segundo esta corrente, o Direito Internacional e o Direito Interno são ordens jurídicas distintas e independentes umas das outras, representando as normas internacionais apenas compromissos exteriores do Estado, assumidos por governos na sua representação, sem que isso possa influir de forma automática na ordem jurídica interna estatal, se o todo pactuado não se incorporar seguindo o processo constitucionalmente previsto. Desta forma, o conceito de soberania, concretização do poder supremo do Estado, explica a esfera de Direito Internacional que, sempre de forma precária e mediante uma cessão voluntária do Estado, protege os interesses nacionais (SALA, 2007, p. 30).
} 
Em segundo lugar, o isolamento das negociações de paz fora do âmbito das Nações Unidas contribuiu para a continuidade do conflito e para o favorecimento da parte mais forte da disputa, uma vez que as possíveis soluções via CSNU eram barradas. Politicamente e militarmente, Israel e Palestina não são comparáveis, pois o primeiro tende a prevalecer, seja no que se refere a sua capacidade de articular-se com outros atores estatais e obter apoio aos seus interesses, seja pela sua organização e capacidade militar e econômica, que possibilitam o domínio sobre áreas territoriais que pertencem ao que deveria ser o Estado palestino. As tentativas de decidir a questão no CSNU foram (e ainda são) vetadas pelos Estados Unidos - parceiro estratégico do Estado de Israel ${ }^{11}$. "[...] Washington dá apoio diplomático consistente a Israel. Desde 1982, os Estados Unidos vetaram 33 resoluções do Conselho de Segurança das Nações Unidas críticas a Israel, um número maior do que o total combinado dos vetos exercidos por todos os outros membros do Conselho de Segurança" (MEARSHEIMER e WALT, 2006, p. 31). Nesse contexto, a importância atribuída às negociações como representativas do princípio da não intervenção apenas viabilizou o descumprimento do direito internacional aplicável ao conflito.

Em terceiro lugar, postergar uma solução para a situação dos refugiados palestinos até que um acordo final fosse negociado entre Israel e Palestina - mesmo diante do constante aumento do número de refugiados, do cerceamento de direitos via ocupação militar, da violência desproporcional e do desinteresse do Estado de Israel pelo retorno dos palestinos - reforçou o posicionamento de Israel, que prioriza a manutenção da maioria étnica judaica em seu território e permitiu a expansão da ocupação militar com pretensões de anexação de áreas fundamentais dos territórios palestinos.

A burocratização gerou uma cisão político-social da questão Palestina em duas dimensões: a política, representada pela estrutura e normatividade da ONU/UNRWA, e a social, representada pela práxis da assistência humanitária (Figura 2). De um lado uma burocracia que opera paralelamente à práxis e de outro a realidade da prolongada assistência humanitária que demanda soluções concretas (e muitas vezes imediatas) para além da normatividade existente. O efeito perverso gerado foi a politização da questão Palestina sem mudanças reais na situação dos refugiados palestinos. Ao contrário, sua condição tem se agravado ao longo das décadas em relação aos três pontos de disputa (território, direito de retorno e ocupação militar) enquanto aguardam, sem previsão, por uma solução permanente. $O$ resultado da burocratização é o adiamento de uma solução para o conflito, uma vez que a UNRWA funciona de modo análogo a um Estado palestino.

\footnotetext{
${ }^{11}$ Para um estudo detalhado dessa parceria Estados Unidos-Israel e suas implicações para a Questão Palestina, ver MEARSHEIMER e WALT, 2006 e 2007; MEARSHEIMER, 2008.
} 


\section{FIGURA 2 - A BUROCRATIZAÇÃO E A CONSEQUENTE CISÃO POLÍTICO-SOCIAL DA QUESTÃO PALESTINA NA ONU (1947-2016)}

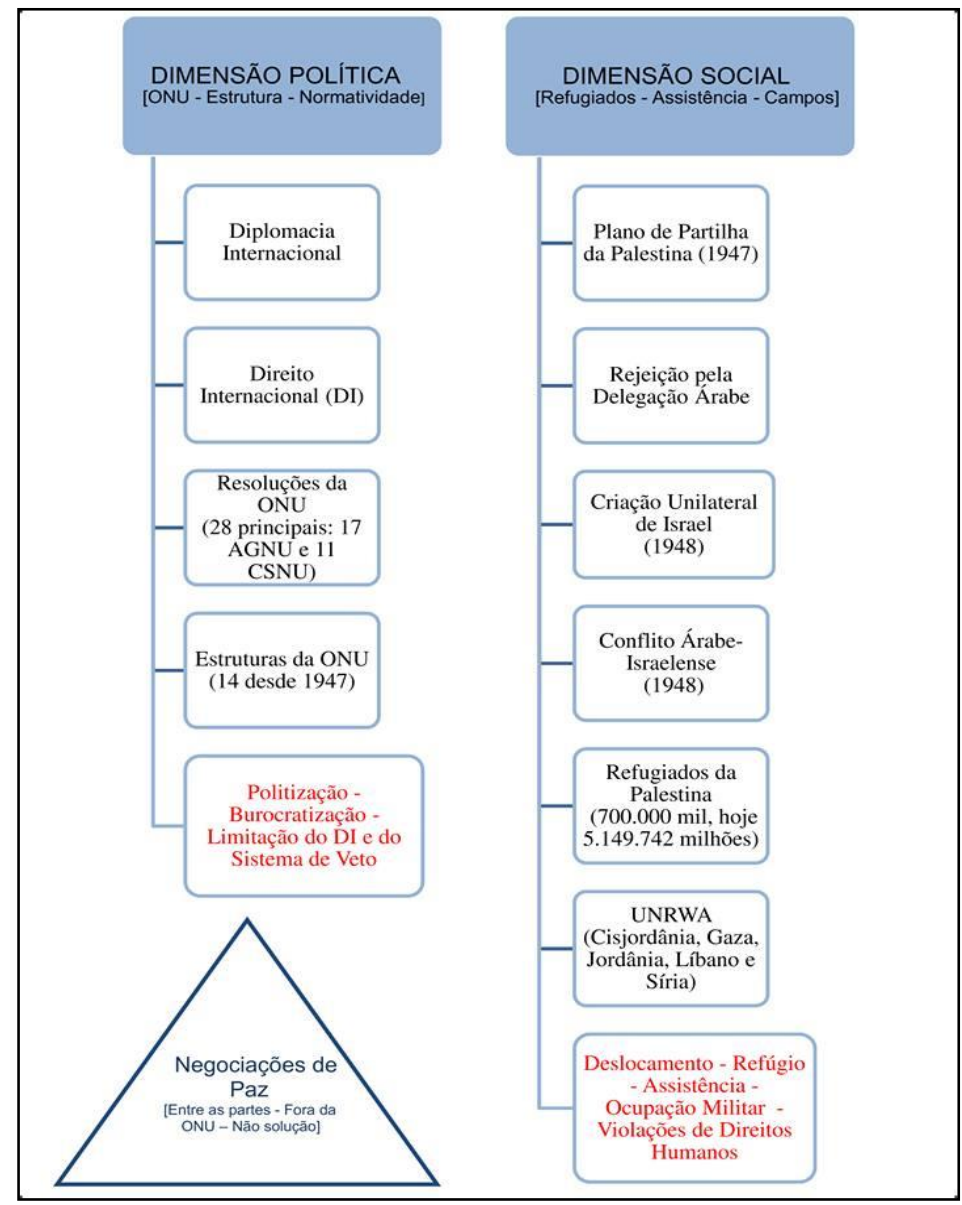

Fonte: Elaboração própria (2016).

A Figura 2 ilustra as dimensões da cisão político-social da questão Palestina. A dimensão políticonormativa caracteriza-se pelo engajamento diplomático dos Estados em prol de uma solução para o conflito e para a situação dos refugiados palestinos, mas que gerou (e ainda gera) uma grande quantidade de resoluções, principalmente na Assembleia Geral, e criou estruturas especializadas no tratamento da questão. No entanto, apesar dos esforços, a dimensão político-normativa tem apenas resultados simbólicos, uma vez que as recomendações da ONU e as normas internacionais são ignoradas por Israel, e concorre com a dimensão social, ou seja, com a realidade dos refugiados palestinos e da assistência humanitária. Ademais, é um tema que ainda suscita polêmica e polarização na política internacional.

A dimensão social, por sua vez, caracteriza-se pela própria história do conflito e da realidade dos refugiados palestinos, dos inúmeros obstáculos para a realização dos seus direitos e das demandas socioeconômicas em função da ocupação militar e das violações de direitos humanos. Essas dimensões reforçam-se mutuamente na medida em que a normatividade gera novas estruturas e práticas humanitárias e a realidade do refúgio e da ocupação demanda nova e adequada normatividade. Finalmente, a cisão provocada pela burocratização da questão Palestina na ONU/UNRWA contribuiu 
para a prolongada assistência humanitária aos refugiados palestinos. A próxima seção apresentará um panorama da assistência humanitária prestada pela UNRWA.

\section{O CASO DA PROLONGADA ASSISTÊNCIA HUMANITÁRIA DA UNRWA}

A assistência humanitária aos refugiados palestinos foi necessária para proteger os indivíduos afetados pelo conflito Árabe-Israelense de 1948. A UNRWA começou a operar nas cinco áreas de concentração e recepção dos refugiados da Palestina dois anos após o início do conflito. Sua fundação e mandato estão diretamente relacionados à questão palestina e, por essa razão, utilizam uma definição de refugiado específica: "refugiados da Palestina são aquelas pessoas que tinham como seu local de residência a Palestina entre junho de 1946 e maio de 1948, que perderam tanto suas casas quanto seus meios de sobrevivência, como resultado do conflito de 1948", bem como seus descendentes (UNRWA(b), 2015).

A assistência aos refugiados palestinos teve início em 1950 na Cisjordânia - incluindo Jerusalém Oriental, Faixa de Gaza, Jordânia, Líbano e Síria, e seu mandato é estritamente humanitário, ou seja, a agência não tem autoridade para negociar ou resolver a disputa. $O$ atual mandato ${ }^{12}$, prolongado até 30 de junho de 2020, determina que a UNRWA preste assistência e serviços de proteção e promova o desenvolvimento humano dos refugiados palestinos deslocados pelo conflito de 1967. A agência oferece serviços de assistência social, saúde, educacionais, microfinanciamentos e auxílio de emergência, proteção, infraestrutura e melhoria dos campos de refugiados. Atua em conjunto com os doadores, países receptores e refugiados. É responsável apenas pelos serviços prestados (dentro e fora dos campos), sendo os campos de refugiados de propriedade e responsabilidade dos países receptores, bem como a segurança e a ordem no interior deles (UNRWA FAO, 2016).

O orçamento da agência é quase todo oriundo de doações voluntárias dos Estados membros das Nações Unidas e é distribuído entre os principais programas, sendo a maior parte destinada à educação (UNRWA(b), 2015). Além disso, funciona, também, em parceria com outras agências, organizações não governamentais e sociedade civil. Esta subsidiária da ONU diferencia-se de outras agências na medida em que presta assistência diretamente aos seus beneficiários, os quais também fazem parte do quadro de funcionários. A UNRWA é um dos maiores programas da ONU, com aproximadamente 30.000 mil funcionários nas cinco áreas de operação - mais de 28.000 mil são os próprios refugiados (UNRWA FAQ, 2016).

\footnotetext{
A UNRWA é única no seu compromisso de longa data com um grupo de refugiados e suas contribuições para o bem-estar e desenvolvimento humano por quatro gerações de refugiados palestinos. [...] O trabalho da UNRWA exemplifica um compromisso internacional para o desenvolvimento humano dos refugiados palestinos ajudando-os a:
}

\footnotetext{
${ }^{12} \mathrm{O}$ mandato original estabelecia que a UNRWA prestasse "assistência direta e [oferecesse] programas de obras em colaboração com os governos locais, consultasse os governos do Oriente Médio sobre as medidas a serem tomadas em preparação para o momento em que a assistência internacional e projetos de obras já não estivessem disponíveis, e planejasse para o momento em que a assistência não fosse mais necessária" (UNRWA FAQ, 2016).
} 
adquirir conhecimentos e habilidades, levar uma vida longa e saudável, alcançar níveis de vida decentes [e] a usufruir dos direitos humanos em toda a extensão possível (UNRWA(c), 2011, p. 4).

A UNRWA assiste tanto os refugiados que vivem em um dos 58 campos quanto os refugiados registrados apenas como beneficiários dos serviços oferecidos. A agência é responsável por 5.589.488 de beneficiários registrados, dos quais 5.149 .742 são refugiados e 439.746 outros indivíduos (UNRWA(b), 2015). Além dos programas regulares oferecidos pela agência nas áreas de educação, saúde, assistência social e microfinanciamento, outros programas de emergência são desenvolvidos na Cisjordânia e na Faixa de Gaza devido aos enfrentamentos e às restrições impostas, respectivamente, pela ocupação militar e pelo bloqueio israelenses que demandam a reconstrução dos patrimônios destruídos em enfrentamentos e soluções para o empobrecimento generalizado da população palestina.

O conflito na Síria exigiu novos programas emergenciais e chamados aos doadores para lidar com a nova situação de vulnerabilidade, dependência exclusiva da agência e redeslocamento de refugiados dos campos sírios (UNRWA(d), 2015, p. 12). "Operações de emergência foram realizadas na Cisjordânia e em Gaza desde a eclosão da Segunda Intifada, em 2000, e na Síria, Líbano e Jordânia desde junho de 2012, como parte do Plano de Resposta Humanitária Regional Síria" (UNRWA(e), 2016). Os beneficiários mais vulneráveis recebem ajuda financeira, itens básicos de alimentação e oportunidades de trabalho temporário. Os programas da agência são atualizados para atender as demandas socioeconômicas e contornar obstáculos, de modo a promover o desenvolvimento humano nas áreas em que atua. Os refugiados que se encontram fora das áreas de atuação da agência são assistidos pelo Alto Comissariado das Nações Unidas para os Refugiados (ACNUR) (UNRWA FAO, 2016). A Tabela 1 apresenta, resumidamente, os quatro principais programas da agência.

TABELA 1 - PRINCIPAIS PROGRAMAS REGULARES DA UNRWA EM NÚMEROS (2015)

\begin{tabular}{|c|c|c|c|c|}
\hline PROGRAMAS & Educação & Saúde & $\begin{array}{c}\text { Assistência e serviços } \\
\text { sociais }\end{array}$ & $\begin{array}{c}\text { Microfinanciamento } \\
\text { (Gaza \& Cisjordânia) }\end{array}$ \\
\hline Beneficiários atendidos & $\begin{array}{l}493.500 \text { estudantes } \\
(49.9 \% \text { alunas })\end{array}$ & $\begin{array}{c}9.457 .155 \\
\text { pacientes anuais }\end{array}$ & $\begin{array}{c}294.152 \text { casos de } \\
\text { necessidade (SSNP) }\end{array}$ & $\begin{array}{c}34.967 \text { (2014) } \\
\text { (359.961 empréstimos) }\end{array}$ \\
\hline Funcionários & 21.924 professores & 3.338 atendentes & 919 atendentes & 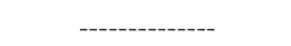 \\
\hline Estrutura & $\begin{array}{c}677 \text { escolas } \\
+ \\
08 \text { centros de } \\
\text { treinamento } \\
\text { vocacional } \\
+ \\
02 \text { Faculdades de } \\
\text { Ciência da Educação }\end{array}$ & $\begin{array}{c}137 \text { clínicas } \\
+ \\
110 \text { clínicas } \\
\text { odontológicas }\end{array}$ & $\begin{array}{c}04 \text { centros comunitários } \\
\text { de desenvolvimento } \\
+ \\
61 \text { centros do programa } \\
\text { das mulheres } \\
+ \\
37 \text { centros comunitários } \\
\text { de reabilitação }\end{array}$ & 23 filiais de operações \\
\hline Recursos investidos & 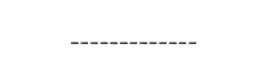 & ----- & ------ & $\begin{array}{l}\text { US\$ 402,563,386 } \\
\text { em empréstimos }\end{array}$ \\
\hline
\end{tabular}

Fonte: Elaboração própria, com base nos dados disponíveis em UNRWA(d), 2015. 
A UNRWA é responsável por um dos maiores sistemas educacionais do Oriente Médio, proporcionando educação básica e gratuita em 677 escolas para 493.500 estudantes nas cinco áreas de atuação. Mais da metade do orçamento da agência é para a educação. Além do ensino básico, oferece ensino técnico (moda, farmácia, carpintaria, arquitetura etc.), treinamento vocacional e duas Faculdades de Ciência da Educação (Cisjordânia e Jordânia). Desde 2000, como parte da reforma educacional da agência, foi incluída a educação em direitos humanos a fim de "promover a não violência, habilidades de comunicação saudáveis, resolução pacífica de conflitos, direitos humanos, tolerância e boa cidadania", especialmente na Faixa de Gaza. Apesar de ser um grande sistema educacional, há demanda por outras 100 escolas, uma vez que metade dos refugiados palestinos é menor de 25 anos e nove entre dez delas precisam oferecer dois turnos $-73,9 \%$ das escolas na Faixa de Gaza (UNRWA(f), 2016; UNRWA AOR, 2015).

O programa de saúde oferece serviços médicos básicos, atendimento psicológico, obstetrícia, fisioterapia etc., com acesso universal aos serviços de saúde integral. Desde 2003 também é responsável pelo controle de qualidade da água, saneamento e outros serviços fundamentais em áreas isoladas e afetadas por conflitos, pelas restrições da ocupação e nos campos de refugiados (UNRWA(d), 2015).

O programa de assistência social oferece proteção aos refugiados palestinos mais vulneráveis, especialmente mulheres, crianças, pessoas com deficiência e idosos em situação de extrema pobreza. Dos refugiados que se encontram em situação de pobreza absoluta (estimados 1.200 .000 indivíduos) e de extrema pobreza (estimados 700.000 indivíduos), 294.152 indivíduos de 70.000 famílias receberam cestas básicas e ajuda financeira complementar pelo programa de segurança social (SSNP) ${ }^{13}$. Ademais, a agência é responsável pela preservação de 17.000 .000 de documentos dos refugiados, como certidões de nascimento e escrituras de propriedades. Muitos desses documentos são anteriores ao conflito de 1948 , a fim de garantir o acesso aos direitos prescritos pelo Direito Internacional dos Refugiados (DIR) (UNRWA(g), 2016).

O microfinanciamento estimula a 'geração de renda sustentável' por meio de empréstimos aos refugiados palestinos e outros grupos marginalizados para a criação e manutenção de pequenos negócios, formais ou informais. Esse programa também promove a autonomia de jovens entre 18 e 30 anos por meio de empréstimos para as chamadas start-ups (UNRWA(h), 2016).

Outro programa oferecido pela UNRWA responde pela infraestrutura e melhorias nos 58 campos de refugiados, nos quais vivem aproximadamente 1.603 .018 beneficiários. Os próprios refugiados trabalham nas melhorias decididas pela comunidade, com ênfase na atualização das antigas 'tendas' e nas necessidades de mulheres, crianças e pessoas com deficiência, e também na restauração das estruturas danificadas pelos conflitos ou desastres naturais (UNRWA(i), 2016).

Além desses quatro programas, há também os programas de emergência - normalmente de curta duração - que são postos em prática conforme a necessidade de resposta aos conflitos resultantes

${ }^{13}$ SSNP - Social Safety Net Programme. 
da ocupação militar israelense na Cisjordânia, dos frequentes enfrentamentos entre o Hamas e Israel na Faixa de Gaza, do conflito entre o Hamas e as Forças Armadas Libanesas em 2007 e, desde 2011, do conflito na Síria (UNRWA(j), 2016). As necessidades básicas e situações de emergência variam em cada uma das cinco áreas de atuação. Os registros da UNRWA são apresentados, resumidamente, na Tabela 2:

TABELA 2 - ÁREAS DE ATUAÇÃO DA UNRWA EM NÚMEROS (DE $1^{\circ}$ JANEIRO 2015) $)^{14}$

\begin{tabular}{|l|c|c|c|c|c|}
\hline \multicolumn{1}{|c|}{ UNRWA } & Cisjordânia & Faixa de Gaza & Jordânia & Líbano & Síria \\
\hline Refugiados registrados & 792.081 & 1.276 .929 & 2.117 .361 & 458.369 & 560.000 \\
Campos de refugiados & 19 & 08 & 10 & 12 & 09 \\
Escolas (no de alunos) & $97(50.566)$ & $257(250.000)$ & $174(118.546)$ & $68(38.173)$ & $44(45.802)$ \\
Centros de treinamento técnico & 02 & 02 & 02 & 01 & 01 \\
Centros de saúde básica & 42 & 22 & 25 & 27 & 15 \\
Centros comunitários de reabilitação & 15 & 06 & 10 & 01 & 05 \\
Centros do programa das mulheres & 19 & 07 & 14 & 08 & 13 \\
\hline
\end{tabular}

Fonte: Elaboração própria, a partir dos dados disponiveis em UNRWA(d) e UNRWA AOR, 2015.

A Tabela 2 revela, em números, o tamanho e a complexidade da assistência humanitária da UNRWA. Cada área de atuação tem suas especificidades e desafios, portanto, é preciso conhecer a realidade na qual a agência opera para compreender o nível de vulnerabilidade e dependência dos refugiados palestinos. A assistência prestada pela agência é similar em todas as áreas, à exceção dos programas de emergência, porém o perfil socioeconômico, as demandas, a violência, as restrições e as violações de direitos humanos diferem entre elas.

Na Cisjordânia são 792.081 refugiados palestinos registrados, com 228.560 vivendo em um dos 19 campos atendidos pela UNRWA - maior número de campos das cinco áreas de atuação. O aumento da violência, principalmente de colonos judeus, das demolições de moradias dos palestinos (incluindo as chamadas 'demolições punitivas') e a remoção de comunidades de beduínos (aproximadamente 46 de maioria refugiada da Palestina) somadas às restrições de acesso às suas terras, aos serviços oferecidos pela agência e ao mercado de trabalho, especialmente na chamada Área $\mathrm{C}^{15}$, consistem no perfil atual dos refugiados palestinos nessa área de atuação (UNRWA AOR, 2015, p. 4; UNRWA West Bank, 2016).

${ }^{14}$ Os números da Síria variam devido ao conflito no país desde 2011. Alguns campos de refugiados foram atingidos durante bombardeios, portanto, várias estruturas, como parte das escolas, precisam ser reconstruídas. Outros campos absorvem alguns refugiados e algumas escolas abrigam temporariamente 4.795 refugiados palestinos da Síria deslocados pelo conflito, bem como outras oferecem dois turnos para atender todos os alunos registrados. Eram 94 escolas da UNRWA e outras disponibilizadas pelo Ministério da Educação da Síria e 23 centros básicos de saúde antes do conflito.

${ }^{15}$ A Cisjordânia foi dividida em três áreas administrativas (A, B e C) pelos Acordos de Oslo de 1993 e 1995 entre Israel e a Organização para a Libertação da Palestina (OLP), as quais seriam transferidas gradualmente da administração da ocupação militar israelense para a Autoridade Nacional Palestina (ANP). Essa transferência, no entanto, não está sendo concretizada. 
Uma economia estagnada, a falta de oportunidades de trabalho e o baixo poder de compra contribuem para a dependência da assistência humanitária para suprir as necessidades mais básicas. A taxa de desemprego dos refugiados palestinos é de 19,3\% (acima da taxa geral da população de 18,5\%) e a dos que vivem nos campos chega a $25,7 \%$. A insegurança alimentar nos campos afeta $29 \%$ dos refugiados, demandando a entrada de 36.139 refugiados e 85 comunidades de beduínos no Programa de Segurança Social (SSNP) para receber alimentos e 95.077 indivíduos (16.499 famílias) para receber 'dinheiro por trabalho' (cash-for-work). Os obstáculos ao movimento de palestinos têm aumentado, particularmente em Hebron e Jerusalém Oriental, essa última parte do sistema israelense de permissão de acesso (Access Permit System) que afeta 80\% da população da Cisjordânia. Ao todo são 95 obstáculos (roadblocks), sendo 19 deles os chamados 'postos de controle militar' (checkpoints) (UNRWA AOR, 2015, p. 5; UNRWA West Bank, 2016).

Na Faixa de Gaza os refugiados palestinos somam 1.276.929, com 560.964 vivendo em um dos 08 campos, uma das maiores densidades populacionais do mundo - o menor campo dessa área de atuação pode ser equiparado ao maior campo da Cisjordânia (Balata). O bloqueio imposto por Israel desde a ascensão do Hamas ao governo, em 2007, é um dos desafios dessa área de atuação. "A taxa de desemprego está entre as mais altas do mundo e $80 \%$ da população depende da assistência internacional" - taxas de $41 \%$ no geral, $43 \%$ entre os refugiados palestinos, $63 \%$ entre os jovens, $63 \%$ entre as mulheres e $84 \%$ entre as mulheres palestinas jovens refugiadas (UNRWA AOR, 2015, p. 4i UNRWA Gaza Strip, 2016).

Instabilidade política, socioeconômica e insegurança generalizada e alimentar exigem priorizar a assistência humanitária aos desalojados pelo conflito de 2014 entre Israel e o Hamas - aproximadamente 900.000 indivíduos no final de 2015. Houve aumento da violência como resposta ao empobrecimento generalizado, até mesmo contra funcionários da agência. A burocracia imposta pelo Estado de Israel dificulta o acesso aos materiais básicos, que devem ser importados, para a reconstrução de casas e outras propriedades destruídas durante o último conflito (UNRWA AOR, 2015, p. 4; UNRWA Gaza Strip, 2016).

O deslocamento interno gera novos custos para a agência e agrava a superlotação nos campos e centros coletivos provisórios. Mais de US\$144 milhões foram distribuídos entre as famílias em caráter de emergência. Estima-se que 90.000 indivíduos (16.000 famílias) permaneciam deslocados no final de 2015. A economia enfraquecida, os altos preços dos alimentos e o baixo poder de compra contribuem para o aumento da insegurança alimentar $-47 \%$ das famílias encontravam-se nessa situação em 2014. As exportações também representam apenas uma pequena fração quando comparadas ao período anterior ao bloqueio - 1.353 caminhões (incluindo 730 transferidos para a Cisjordânia) ou 113 por mês, apenas 10\% da média mensal do período pré-bloqueio (UNRWA AOR, 2015, p. 4; UNRWA Gaza Strip, 2016).

Na Jordânia são 2.117.361 de refugiados palestinos, com 385.418 vivendo em um dos 10 campos o maior número de refugiados palestinos das cinco áreas de atuação da agência. A maioria é nacional do Reino Hashemita da Jordânia, com acesso aos direitos sociais, econômicos e políticos. Entretanto, 150.000 refugiados palestinos oriundos do conflito Israel-Palestina de 1967 na Faixa de Gaza não se 
encontram nessa categoria. Novos fluxos de refugiados afetam a normalmente estável economia e infraestrutura do país. Estima-se que 16.400 'novos' refugiados palestinos da Síria fugiram para a Jordânia após o conflito de 2011, gerando restrições de admissão impostas pelo governo jordaniano 83\% estão em situação de grande vulnerabilidade. Dificuldades de acesso aos serviços básicos e ao trabalho, discriminação e retorno forçado, prática considerada ilegal pelo Direito Internacional dos Refugiados segundo o Princípio de Non-Refoulement, são alguns dos desafios nessa área de atuação. A UNRWA foi a única a oferecer serviços de assistência, de saúde e de registros em 2015, bem como fornecendo ajuda em espécie aos casos mais críticos (UNRWA AOR, 2015, p. 6-7; UNRWA Jordan 2016).

No Líbano, os refugiados palestinos estão entre os mais vulneráveis, pois a maioria necessita de alguma assistência (jurídica ou humanitária) para compensar o acesso negado aos serviços públicos e ao exercício de muitas profissões e ao direito de propriedade devido à apatridia ${ }^{16}$. Nessa área de atuação encontram-se 458.369 refugiados palestinos, com 249.410 vivendo em um dos 12 campos - representam $10 \%$ da população do país, a maior porcentagem de refugiados palestinos em condição de extrema pobreza das cinco áreas de atuação da UNRWA. Estima-se que 93\% deles dependem dos serviços humanitários e regulares da agência, incluindo alimentos, abrigo, serviços de saúde e de educação. Pobreza, dívidas, competição por trabalho, superlotação e falta de infraestrutura nos campos de refugiados são características dessa comunidade no Líbano. O acolhimento de refugiados palestinos da Síria agrava a já precária condição dos campos e também gera novos custos para a agência - 61.709 refugiados em situação de extrema pobreza receberam ajuda pelo SSNP e microfinanciamento, além de 1.100 jovens receberem treinamento vocacional; 41.882 refugiados foram beneficiados com alimentos e em espécie; 11.747 famílias receberam assistência habitacional e outras 10.735 ajuda em espécie para suprir as necessidades durante o inverno (UNRWA AOR, 2015, p. 6; UNRWA Lebanon, 2016).

Na Síria, a vulnerabilidade dos refugiados palestinos é anterior ao conflito de 2011 , com as maiores taxas de mortalidade infantil e menores taxas de matrícula escolar apesar do acesso a muitos dos direitos de cidadãos sírios. Dos 560.000 refugiados registrados pela agência, 450.000 permanecem no país e necessitam de ajuda humanitária, 280.000 estão deslocados internamente e 110.000 deixaram o país em busca de 'novo' refúgio - aproximadamente 42.000 para o Líbano e 16.400 para a Jordânia. Alguns campos estão localizados em áreas de conflito ou inacessíveis, como em Damasco (Yarmouk e Khan Eshieh) ou próximos a Muzayrib e Jillin (Dera-a), que resulta em fragmentação das comunidades e das famílias - 47.00o indivíduos encontram-se nessas áreas. A deterioração da economia, a alta de preços e das taxas de desemprego, a inflação, a falta de alimentos e a desvalorização da moeda nacional resultaram em $95 \%$ dos refugiados palestinos dependentes da assistência humanitária para sobreviver. Os serviços oferecidos pela agência foram afetados pelo conflito, mas não totalmente interrompidos (UNRWA AOR, 2015, p. 5-6; UNRWA Syria, 2016).

\footnotetext{
16 "Ser apátrida significa não possuir nacionalidade ou cidadania. É quando o elo legal entre o Estado e um indivíduo deixa de existir. As pessoas apátridas enfrentam numerosas dificuldades em seu quotidiano: não possuem acesso aos serviços de saúde e educação, direitos de propriedade e direito de deslocar-se livremente. Eles também são suscetíveis a tratamento arbitrário e a crimes como o tráfico de pessoas. Sua marginalização pode criar tensões na sociedade e levar à instabilidade a nível internacional, provocando, em casos extremos, conflitos e deslocamentos" (ACNUR, 2016).
} 
Esse breve panorama dos principais programas regulares da UNRWA, bem como do perfil de cada uma das cinco áreas de atuação, mostra a complexidade e a relevância da assistência humanitária prestada aos refugiados palestinos. Apesar da extensa normatividade internacional relacionada à questão palestina, apresentada na seção anterior, a realidade desses refugiados está muito distante das proposições contidas nas resoluções da ONU. Os dados confirmam aumento da necessidade humanitária ao invés de uma diminuição e consequente resolução do conflito Israel-Palestina, corroborando o argumento de que a UNRWA atua de modo análogo a um Estado. A prolongada assistência aos refugiados palestinos viabilizou não apenas a manutenção como também a expansão do status quo do Estado de Israel em detrimento da independência e da autonomia do povo palestino. A próxima seção analisará as implicações da prolongada assistência da UNRWA para uma solução permanente do conflito e para a segurança internacional.

\section{O IMPASSE DOS REFUGIADOS PALESTINOS PARA A (IN)SEGURANÇA INTERNACIONAL}

A prolongada situação de refúgio dos palestinos permanece como uma questão de segurança internacional, uma vez que não há estabilidade na região de Israel-Palestina e os enfrentamentos nunca cessaram completamente - ainda que não mais envolvam os países árabes vizinhos, como nos conflitos iniciais de 1948 e 1967. Israel e "Palestina" - na figura dos governos da Autoridade Nacional Palestina (ANP, Cisjordânia) e do Hamas (Faixa de Gaza) - estão sempre na iminência de um conflito, além da violência e das restrições sistematizadas e de ataques a bomba (muitos deles suicidas) no cotidiano de palestinos e israelenses.

O adiamento de uma solução permanente da situação dos refugiados palestinos, quando ainda era mais facilmente manejável, gerou um impasse político para a solução permanente do conflito IsraelPalestina. A realidade do refúgio distanciou-se da política internacional, dando lugar à concorrência entre o debate político e as ações realmente executadas em campo. Ao contrário do que alguns autores afirmam (BERGER et. al., 2010, p. 2-12), não houve progresso nas negociações de paz, tampouco na realidade dos palestinos - refugiados ou não. Acordos como Camp David (1978) e Oslo (1993 e 1995), o reconhecimento do Estado de Israel pela Organização para a Libertação da Palestina (OLP), as mediações internacionais e as atribuições simbólicas à "Palestina" (como Estado não membro observador) não cumpriram seus objetivos e apenas serviram à retórica de defesa israelense sem comprometimento com os esforços para a paz. Israel ocupa militarmente o território palestino da Cisjordânia desde o conflito de 1967 e impõe um bloqueio à Faixa de Gaza desde 2007 - território também sujeito à ocupação militar israelense antes do bloqueio. O número de refugiados palestinos apenas aumentou ao longo das décadas. Desde o início dos registros pela UNRWA em 1950 até o ano de 2008 o número de refugiados passou de 914.221 para 4.618.141, representando um aumento de 505\% no período de 58 anos. De 2008 a 2016, o número de refugiados palestinos aumentou 112\%. Nos territórios ocupados da Palestina os problemas enfrentados incluem "ameaças à vida, à liberdade e à segurança, destruição ou danos a casas e outros bens, deslocamento forçado, restrições à liberdade de circulação e 
ao acesso a meios de subsistência, e falta de responsabilização e reparação efetiva" (OCHAOPT, 2015, p. 2).

Os avanços sociais, econômicos e políticos nos territórios palestinos eram (e continuam sendo) inversamente proporcionais à normatividade relacionada à questão Palestina na ONU, apesar da ajuda humanitária da UNRWA. Estruturalmente e normativamente a situação dos palestinos parecia melhorar, mas socialmente a assistência humanitária era (e ainda é) cada vez mais necessária. A cisão políticosocial, apresentada na primeira seção deste artigo, criou um ambiente propício para a expansão da ocupação militar israelense, de modo que, internacionalmente, a questão Palestina estava sendo tratada, mas internamente nenhum acordo foi cumprido e o direito internacional foi ignorado.

O mandato e os programas da UNRWA modificaram-se com o passar das décadas, a fim de atender as demandas locais, lidar com as emergências e desafios da ocupação e da prolongada assistência em campo. Os mandatos contemporâneos têm foco no desenvolvimento humano de seus beneficiários que, em sua maioria, são palestinos e não mais na assistência humanitária, a qual está voltada às áreas da Faixa de Gaza e da Síria devido aos conflitos, respectivamente, nos anos de 2014 e de 2011. A agência deixou de prestar apenas ajuda humanitária de emergência para oferecer serviços regulares de educação, saúde, assistência social, microfinanciamento, obras de infraestrutura e reconstrução pós-conflitos etc., preenchendo a lacuna do Estado da Palestina que não chegou a ser criado.

A assistência da UNRWA é (ainda) imprescindível, dada a dependência de milhares de beneficiários. O papel da agência de prestar assistência humanitária, garantir a proteção e os direitos dos refugiados palestinos e evitar maiores enfrentamentos, como parte do compromisso da comunidade internacional com a segurança, foi (e continua sendo) cumprido. Entretanto, a prolongada ajuda isentou Israel da sua responsabilidade e reforçou a situação de vulnerabilidade dos refugiados palestinos, pois apenas remedia o que precisa de solução permanente, ocupando uma função que deveria ser do Estado palestino.

\section{CONSIDERAÇÕES FINAIS}

Criada inicialmente para prestar assistência humanitária aos refugiados palestinos, a UNRWA tornou-se instrumento que serve aos propósitos dos dois lados envolvidos no conflito árabe-israelense: de um lado, atende as necessidades emergenciais dos refugiados, desempenhando um papel essencial para evitar o agravamento da questão humanitária; de outro, permite ao Estado de Israel o adiamento de uma solução definitiva para o conflito que surgiu após a criação desse Estado no final da Segunda Guerra Mundial. Trata-se do paradoxo resultante de um conflito cuja solução é constantemente adiada, seja pela incapacidade da ONU de conduzir as negociações e levá-las a termo, seja pelos interesses de Estados, como Israel e Estados Unidos, dentre outros fatores. Os dois lados revelam pouco interesse em produzir uma solução definitiva que possa colocar fim em um dos mais importantes conflitos dos séculos XX e XXI. Ao lado disso, a burocratização da questão palestina cresceu ao longo das décadas e expressou-se por 
meio do aumento das normas e das estruturas destinadas à administração dessa questão no interior da ONU.

Dessa forma, o paradoxo da experiência da UNRWA, que procurou ser explicitada neste artigo, expõe as dificuldades do papel da ONU no que se refere à questão palestina. De um lado, motivada por razões humanitárias, Estados membros da ONU destinaram, durante muitas décadas, recursos para viabilizar políticas e programas cujo objetivo era atender as necessidades dos refugiados palestinos. De outro lado, ao promover tais políticas e programas em áreas como saúde e educação, a agência da ONU assumiu funções análogas de um Estado que não foi efetivado pelo Plano de Partilha da Palestina, aprovado em 1947. Dessa maneira, a UNRWA preenche lacunas resultantes da ausência de um Estado cuja fundação poderia contribuir para a solução de um dos conflitos internacionais mais prolongados e complexos das relações internacionais contemporâneas.

Artigo recebido em 11 nov 2018. Aprovado em 18 dez 2018.

\section{REFERÊNCIAS}

ACNUR - Alto Comissariado das Nações Unidas para os Refugiados. O Que é a Apatridia? Disponível em: http://www.acnur.org/portugues/quem-ajudamos/apatridas/o-que-e-a-apatridia/. Acesso em: 23 set. 2016.

ALMOND, Gabriel A.; POWELL Jr., G. Bingham. Uma teoria de política comparada. $2^{a}$ edição. Rio de Janeiro: Zahar Editores, 1980, $206 \mathrm{p}$.

BERGER, Alan et. al. Israel and Palestine, Two States for Two Peoples: If Not Now, When? Boston: Study Group on Middle East Peace, 2010, 94 p.

DI MAURO, Danilo. The Role of the UN in the Arab-Israel Conflict: a Quantitative Analysis. Jean Monnet Working Papers in Comparative and International Politics. Department of Political Studies, University of Catania, November, 2004, JMWP nº 54 .

DPR - Division for Palestinian Rights. The Origins and Evolution of the Palestine Problem - CEIRPP, DPR study, Part I: 1917-1947 (30 June 1978). Disponivel em: https://goo.gl/NFq6gh. Acesso em: 14 set. 2016.

MEARSHEIMER, John J.; WALT, Stephen M. The Israel Lobby and U.S. Foreign Policy. Middle East Policy, Vol XIII, N. 3, 2006, p. 29-87. Disponível em: https://goo.gl/ZnLzGB. Acesso em: 15 jan. 2017.

MEARSHEIMER, John J.; WALT, Stephen M. The Israel Lobby and U.S. Foreign Policy. New York: Farrar, Straus and Giroux, 2007.

MEARSHEIMER, John J. The U.S. Should Act as an Honest Broker. Palestine-Israel Journal of Politics, Economics \& Culture, Vol. 15, Issue 1/2, 2008, p. 147-152. Disponível em: http://mearsheimer.uchicago.edu/pdfs/HonestBroker.pdf. Acesso em: 15 jan. 2017. 
OCHAOPT - United Nations Office for the Coordination of Humanitarian Affairs Occupied Palestinian Territory. Humanitarian Atlas 2015. Disponível em: https://goo.gl/TMHUsm. Acesso em: 15 jan. 2017.

SALA, José Blanes. A política internacional e as regras de Jus Cogens. Revista IMES - Direito, ano VIII, $\mathrm{n}$. 13, jul./dez., 2007, p. 29-36. Disponível em: http://www.corteidh.or.cr/tablas/22297.pdf. Acesso em: 15 jan. 2017.

UN - United Nations. The Question of Palestine and the United Nations. 2. ed. New York: United Nations Department Of Public Information, 2008. Disponível em: https://goo.gl/1f27am .

http://unispal.un.org/pdfs/DPI2499.pdf. Acesso em: 15 jan. 2017.

UNHCR - United Nations High Commissioner for Refugees. Chapter 5 - Protracted Refugee Situations: the search for practical solutions. In: The State of World's Refugees 2006, chapter 5, pp. 105-107.

Disponivel em: http://www.unhcr.org/4a4dc1a8g.html. Acesso em: 15 jan. 2017.

UNICRIO - Centro de Informação das Nações Unidas Rio de Janeiro. Carta das Nações Unidas e Estatuto da Corte Internacional de Justiça, 1945. Disponível em:

http://unicrio.org.br/img/CartadaONU_Versolnternet.pdf. Acesso em: 20 out. 2015.

UNISPAL - United Nations Information System on the Question of Palestine. A/RES/181(II), 29 November 1947. Disponível em: https://goo.gl/JKCDNO. Acesso em: 15 jan. 2017.

S/RES/54 (S/902). 15 July 1948. Disponível em: https://goo.gl/W91DwS. Acesso em: 15 jan. 2017.

. A/RES/302 (IV). 8 December 1949. Disponível em: https://goo.gl/Z6Jon7. Acesso em: 15 jan. 2017.

. A/RES/2535 B. 10 December 1969. Disponível em: https://goo.gl/moJa7t. Acesso em: 15 jan. 2017.

. A/RES/3236 (XXIX). 22 November 1973. Disponível em: https://goo.gl/sUcUvF. Acesso em: 15 jan. 2017.

A/RES/67/19. 04 December 2012. Disponível em: https://goo.gl/LzUWvZ. Acesso em: 15 jan. 2017.

UNRWA - United Nations Relief and Works Agency for Palestine Refugees in the Near East. Who We Are. Disponível em: http://www.unrwa.org/who-we-are. Acesso em: 28 set. 2016.

UNRWA(a) - United Nations Relief and Works Agency for Palestine Refugees in the Near East. Who We Are: Organizational Structure. Disponível em: http://www.unrwa.org/who-we-are/organizationalstructure. Acesso em: 14 set. 2016. 
UNRWA(b) - United Nations Relief and Works Agency for Palestine Refugees in the Near East. UNRWA in Figures 2015. Disponível em: https://goo.gl/Pf7XMd. Acesso em: 28 set. 2016.

UNRWA(c) - United Nations Relief and Works Agency for Palestine Refugees in the Near East. Programme Coordination and Support Unit, November 2011. UNRWA Statistics 2010. Disponível em: http://www.unrwa.org/userfiles/2011120434013.pdf. Acesso em: 21 set. 2016.

UNRWA(d) - United Nations Relief and Works Agency for Palestine Refugees in the Near East. About UNRWA 2015. Disponível em: https://goo.gl/HCXSR7. Acesso em: 28 set. 2016.

UNRWA(e) - United Nations Relief and Works Agency for Palestine Refugees in the Near East. How You Can Help: How We Spend Our Funds. Disponivel em: http://www.unrwa.org/how-you-can-help/how-wespend-funds. Acesso em: 22 set. 2016.

UNRWA $(f)$ - United Nations Relief and Works Agency for Palestine Refugees in the Near East. What We Do: Education. Disponivel em: http://www.unrwa.org/what-we-do/education. Acesso em: 22 set. 2016.

UNRWA(g) - United Nations Relief and Works Agency for Palestine Refugees in the Near East. What We Do: Relief and Social Services. Disponível em: http://www.unrwa.org/what-we-do/relief-social-services. Acesso em: 23 set. 2016.

UNRWA(h) - United Nations Relief and Works Agency for Palestine Refugees in the Near East. What We Do: Microfinance. Disponível em: http://www.unrwa.org/what-we-do/microfinance. Acesso em: 23 set. 2016.

UNRWA(i) - United Nations Relief and Works Agency for Palestine Refugees in the Near East. What We Do: Infrastructure and Camp Improvement. Disponivel em: http://www.unrwa.org/what-wedo/infrastructure-camp-improvement. Acesso em: 23 set. 2016.

UNRWA(j) - United Nations Relief and Works Agency for Palestine Refugees in the Near East. What We Do: Emergency Response. Disponivel em: http://www.unrwa.org/what-we-do/emergency-response. Acesso em: 23 set. 2016.

UNRWA AOR - United Nations Relief and Works Agency for Palestine Refugees in the Near East. Reports: Annual Operational Report 2015. Disponível em: https://goo.gl/y2gUi5. Acesso em: 24 set. 2016.

UNRWA Brasil - Agência das Nações Unidas de Assistência aos Refugiados da Palestina. Metade das Escolas da UNRWA Foram Afetadas por Conflitos nos Últimos Cinco Anos (17 de junho de 2016). Disponível em: http://unrwa.org.br/2016/o6/metade-das-escolas-da-unrwa-foram-afetadas-por-conflitos-nosultimos-cinco-anos/. Acesso em: 14 set. 2016.

UNRWA FAQ - United Nations Relief and Works Agency for Palestine Refugees in the Near East. Who We Are: Frequently Asked Questions. Disponível em: http://www.unrwa.org/who-we-are/frequentlyasked-questions. Acesso em: 14 set. 2016. 
UNRWA Gaza Strip - United Nations Relief and Works Agency for Palestine Refugees in the Near East. Where We Work: Gaza Strip. Disponível em: http://www.unrwa.org/where-we-work/gaza-strip. Acesso em: 24 set. 2016.

UNRWA Jordan - United Nations Relief and Works Agency for Palestine Refugees in the Near East.

Where We Work: Jordan. Disponível em: http://www.unrwa.org/where-we-work/jordan. Acesso em: 24 set. 2016.

UNRWA Lebanon - United Nations Relief and Works Agency for Palestine Refugees in the Near East. Where We Work: Lebanon. Disponível em: http://www.unrwa.org/where-we-work/lebanon. Acesso em: 24 set. 2016.

UNRWA Syria - United Nations Relief and Works Agency for Palestine Refugees in the Near East. Where We Work: Syria. Disponível em: http://www.unrwa.org/where-we-work/syria. Acesso em: 24 set. 2016.

UNRWA West Bank - United Nations Relief and Works Agency for Palestine Refugees in the Near East. Where We Work: West Bank. Disponível em: http://www.unrwa.org/where-we-work/west-bank. Acesso em: 24 set. 2016.

UNSC - United Nations Security Council. The Security Council. Disponível em: http://www.un.org/en/sc/. Acesso em: 16 set. 2016. 